\title{
An Analysis of the Factors Affecting the Online Reviews Helpfulness -A Empirical Study based on Jumei.com
}

\author{
Xi-Ya FENG ${ }^{1, \text { a }}$ \\ ${ }^{1}$ School of Business, Jiangxi Normal University, Nanchang, China \\ afengxiya186@126.com
}

Keywords: Online reviews helpfulness, Influence factors, E-commerce.

Abstract. From three dimensions of reviews features,reviewers and readers, an empirical study on 361 valid samples of Jumei.com,to discuss the affecting factors of online reviews helpfulness. The results show that text length, reviewer rating and response number have significant positive impact on review helpfulness, review extremity has a significant negative impact on the helpfulness of the review,but review length of the title has no impact on review helpfulness.

\section{Introduction}

With the rapid development of the Internet, online shopping has become the most fashionable trend. According to the Advisor Channel survey, 91\% of the potential consumers in the purchase of goods or services before the need to refer to other consumer online reviews. Facing a large number of review information, consumers should be how to identify their most valuableinformation? In this regard, useful review occupies a very important position[1], and the key to solving this problem is to study the influence factors of the usefulness of online reviews. In view of this, this paper on the basis of the existing research literature, around the "specific factors how to affect online review usefulness?" starting from the three dimensions of reviews features,reviewers and readers to build a theoretical model, then do the empirical analysis. In order to expand the theoretical research on reviews helpfulness, and to promote consumers to achieve the highest objective.

\section{Research model and hypothesis}

\section{Research model}

Based on the existing literature, this study constructs a theoretical model of the online reviews helpfulness. As shown in Fig. 1.

\begin{tabular}{|c|}
\hline Reviews features \\
\hline Review extremity \\
\hline Title length \\
\hline Rext length \\
\hline Reviewers features \\
\hline Response number
\end{tabular}

Fig.1. Research Model on Online Reviews Helpfulness 


\section{Research hypothesis}

Review extremity

Compared to extreme review, a neutral review will be considered the expression is not clear, resulting in recognition is not high[2]. We therefore hypothesize $\mathrm{H} 1$ : extreme reviews have positive impact on reviews helpfulness.

\section{Review length}

Mudambi (2010)found that longer reviews contain more information about the product, and review length of the positive impact on review helpfulness [3]. Thereby, it is proposed that the hypothesize $\mathrm{H} 2$ and H3:review title length and text length have positive impact on reviews helpfulness.

\section{Reviewer rating}

Shuang Yang (2013) studied on reviews helpfulness, The conclusion that the higher the reviewer community status, the higher the online reviews helpfulness [4]. We hypothesize H4:reviewer rating positive influence on the reviews helpfulness

\section{Response number}

The Internet interaction has a significant positive effect on the purchase intention of consumers. In response to the reader, readers are mainly to search for more useful information in order to enhance the confidence in the process of shopping. We hypothesis H5:readers respond have significant positive impact on reviews helpfulness.

\section{Variable measurement and data collection}

Based on the established model, consumers can click on the comment below the "useful" to vote for reviews on jumei.com, this text draws lessons from the research of Racherla, the votes of helpful reviews as the dependent variable [5]. A total of 5 independent variables: review extremity(1 5), title length,text length, reviewer rating (from low to high 1 4), response number, and the introduction of review length of time as control variable.

Grab for skin care,cosmetics, and personal care of different types of popular products as the object of data collection, due to the limitations of time and energy, from the date of publication to the collection of a total of 586 reviews. Taking into account the collected data, some reviews helpfulness of the click rate is too low, in order to ensure that the selected representative reviews, rejecting review helpfulness fewer votes (less than 1), obtained a total of 361 reviews as the final analysis of the data.

\section{Data analysis and results discussion}

Data collected by jumei.com in the comments, using SPSS 20 statistical analysis software for analysis. First, the data samples were used to carry out descriptive statistics. Next, we use multiple regression analysis to validate the model. Finally, according to the data of the discussion and analysis.

\section{Descriptive statistics}

Descriptive statistical analysis of the independent variables and the dependent variables in the data sample, as shown in table 1. 
Table 1. descriptive statistics

\begin{tabular}{cccccc}
\hline & $\mathrm{N}$ & Minimum & Maximum & mean & standard deviation \\
Review extremity & 361 & 0 & 2 & 0.40 & .472 \\
Title length & 361 & 2 & 34 & 10.42 & 5.190 \\
Text length & 361 & 10 & 3412 & 455.05 & 406.504 \\
Reviewer rating & 361 & 1 & 4 & 3.21 & .922 \\
Response number & 361 & 0 & 174 & 6.57 & 14.439 \\
Helpfulness & 361 & 1 & 831 & 13.46 & 63.998 \\
Valid N & 361 & & & & \\
\hline
\end{tabular}

From table 1 analysis results indicate: the average extreme review for 0.4 , Most of the comments in the sample data are neutral; reviewers rated higher, more consumers participate in the reviews, from that,reviewer rating reflects consumers access to high status in the reviews on the platform of jumei.com.Other critics argue that the main factors of reliable; review helpfulness minimum is 1 , the maximum is 831 , the average is 13.46 , from the selected sample, after reading reviews,consumers no more to participate in the vote, but does not rule out the reviews helpfulness of the phenomenon is not high.

\section{Regression analysis}

The multiple regression method was used to verify the influence of each factor on reviews helpfulness, so as to make a quantitative analysis of the variables, and finally determine the linear relationship between them. The results of regression analysis are shown in Table 2.

Table 2. Regression results for all samples

\begin{tabular}{|c|c|c|c|c|c|c|}
\hline & \multirow{2}{*}{ Model } & \multicolumn{2}{|c|}{$\begin{array}{c}\text { Unstandardized } \\
\text { Coefficients }\end{array}$} & \multirow{2}{*}{$\begin{array}{c}\text { Standardized } \\
\text { Coefficients } \\
\text { Beta }\end{array}$} & \multirow{2}{*}{$\mathrm{t}$} & \multirow{2}{*}{ Sig. } \\
\hline & & B & $\underset{r}{\text { Std.Erro }}$ & & & \\
\hline \multirow{7}{*}{1} & (Constant) & 24.996 & 6.520 & & 3.834 & .000 \\
\hline & Review extremity & -.754 & .216 & -.449 & -3.575 & .000 \\
\hline & Title length & -.008 & .016 & -.073 & -.219 & .053 \\
\hline & Text length & .023 & .007 & .144 & 3.245 & .001 \\
\hline & Reviewer rating & .004 & .039 & .023 & 3.700 & .000 \\
\hline & Response number & .327 & .172 & .163 & 9.202 & .000 \\
\hline & length of time & -.005 & .004 & -.028 & -1.053 & .040 \\
\hline
\end{tabular}

a. Dependent Variable: Helpfulness

Table 2 shows the regression estimates of our research model.The coefficient of text length, reviewer rating and response number are positive,indicating that these factors and review helpfulness positive;for reviewer rating, the purchase of cosmetics diamond member users are higher than ordinary members of the users' review helpfulness. The coefficient of the review extremity is negative, which is just the opposite of the positive effect of the previous hypothesis. In addition, there is no correlation between title length and review helpfulness.

Our study shows that the hypothesis proposed in this paper, H3、H4、H5 are supported, but $\mathrm{H} 1$ and $\mathrm{H} 2$ are not passed.

\section{Conclusions and suggestions}

The results show that text length, reviewer rating and response number have significant positive impact 
on reviews helpfulness, review extremity has a significant negative impact on the helpfulness of reviews, but review length of the title has no impact on reviews helpfulness.

This study not only enriches the theoretical model of online review helpfulness, but also has an important practical significance for the management of the online review system. According to the research results, this paper from the characteristics of reviews, reviewers and readers, put forward suggestions about how to improve the usefulness of reviews. First of all, in order to search for potential consumers, enterprises should pay attention to the neutral comments, take necessary measures to set up the score column; secondly, enterprises need strengthen the construction of the reviews system, take incentive measures to encourage the reviewers published more words and the amount of information on the content of reviews.And this kind of long-term incentive method for enhancing the level of reviewers will play a large role; finally, in response, setting up reasonable mechanism, actively promote readers' communication and interaction in the review system.

There are also some shortcomings in the study, this paper only selected experience goods as the research object, and does not take into account the search goods, in reviewer characteristics, not for their personal factors, such as: reviewers education and age characteristics.Thus, we can use the combination of online data collection and questionnaire method, which are to be further empirical research.

\section{Acknowledgements}

This paper was financially supported by the Graduate Innovation Foundation of Jiangxi Normal University(YC2015-S138).

\section{References}

[1] Ying Qian.The impact of online review from semantic orientation on the purchasing decision[J]. Commercial Research, 2015 (6): 133-137.(In Chinese)

[2] Siqing Zhuo, Yongzhou Feng.Empirical study of online consumer review helpfulness determinant determinants--based on hotel review data of Tripadvisor.com[J].Journal of Modern Information,2015,35(4):52-56.(In Chinese)

[3] Mudambi S M , Schuff D . What makes a helpful online review?A study of customer reviews on Amazon.com[J].MIS Quarterly,2010,34(1):185-200.

[4] Shuang Yang.The impact of R\&D investments on patent technology transfer activ ities of local universities --based on the empirical analysis of provincial panel data[J].Management Review, 2013,25(5):136-143.(In Chinese)

[5] Racherla P , Friske W . Perceived 'usefulness' of online consumer reviews:An exploratory investigation across three services categories [J].Electronic Commerce Research and Applications, 2012,11(6):548-559. 